\title{
Seller - Buyer Supply Chain Games Where Shortage Are Permitted
}

\author{
Xu Zhang \\ School of Mathematical and Geospatial Sciences, RMIT University \\ GPO Box 2476, Melbourne VIC 3001, Australia \\ E-mail: xu.zhang@rmit.edu.au \\ Panlop Zeephongsekul (Corresponding author) \\ School of Mathematical and Geospatial Sciences, RMIT University \\ GPO Box 2476, Melbourne VIC 3001, Australia \\ Tel: 61-3-9925-3224Ｅ-mail: panlopz@rmit.edu.au
}

Maryam Esmaeili

Department of Industrial Engineering, Alzahra University, Tehran, Iran

E-mail: esmaeili_m@alzahra.ac.ir

Received: September 14, 2012

Accepted: September 30, 2012

Online Published: October 31, 2012

doi:10.5430/jms.v3n4p1

URL: http://dx.doi.org/10.5430/jms.v3n4p1

\begin{abstract}
In the area of seller-buyer supply chain management, researchers have been very active in seeking optimal policies for both players to achieve a favorable outcome. Most studies are based on somewhat unrealistic assumptions such as deterministic demand and unpermitted shortages. In reality, due to factors such as irregular production capacity or unanticipated demands, shortages will occur, and it will influence both players' decisions. In this paper, we include shortage as a decision variable determined by the seller, and demand is assumed sensitive to both selling price and marketing expenditure. The interaction between seller and buyer will be investigated as non-cooperative Stackelberg game, and the cooperation between seller and buyer will be explored based on Pareto-efficient solution concept. Consequences of the non-cooperative and cooperative aspects of these games will be compared and finally, numerical examples and sensitivity analysis will be presented to compare between models with and without shortages.
\end{abstract}

Keywords: Supply chain, Game theory, Stackelberg game, Inventory, Optimization, Shortages

\section{Introduction and Literature Review}

A seller - buyer supply chain, also refers to as a manufacturer - retailer supply chain (Li et al., 2002), represents an idealized refinement of a process whereby the manufacturer wholesales a product to a retailer, who then retails it to the consumer (Yang \& Zhou, 2006; Chen et al., 2006; Dai et al., 2005). The supply chain system has been discussed and developed by many researchers during the last few decades and they incorporated strategies such as seller buyer coordination, information sharing and business process management (Juttner et al., 2007). Much research have also gone into finding the optimal seller's and buyer's policies related to variables such as selling prices, order quantities and marketing expenditures. Supply chains that were considered can be classified into two-level supply chains which only involve single seller and buyer (Lau \& Lau, 2005; Esmaeili et al., 2009) or multi-level supply chain where there are at least two sellers or buyers (Gao \& Liu, 2008; Jaber \& Goyal, 2008). The supply chain models in this paper will all be two-level.

In recent years, several supply chain mechanisms have been discussed in the literature such as quantity discount, credit option, return policies, quantity flexibility and commitment of purchase quantity (Sarmah et al., 2006; Weng, 1995; Chiang et al., 1994) and they are all related to pricing. For example, a model where demand is price sensitive has been proposed by Abad (1994) who provided a procedure of finding the optimal policy for both seller and buyer 
under a cooperative structure. Similarly, the models used by Freeland (1982), Lee \& Kim $(1993,1998)$ and Sadjadi et al. (2005) assumed that demand is influenced by marketing expenditure and price. Abad \& Jaggi (2003) have considered the possibility of using trade credit to achieve coordination in the seller-buyer supply chain and introduced a procedure for determining the buyer's lot size and retail price. Corbett \& de Groote (2000) and Viswanathan \& Wang (2003) have shown that under a non-cooperative structure, coordination can be achieved through quantity discounts. In all these studies, the interaction between seller and buyer is ignored. However, Esmaeili et al. (2009) and Esmaeili \& Zeephongsekul (2010) investigated interaction between seller and buyer in a supply chain using both a non-cooperative and a cooperative game-theoretical approach, with symmetric and an asymmetric information pattern respectively.

After reviewing the existing literature in the field, it is noticeable that in all the papers referenced, shortages are not permitted. But in reality, shortages will inevitably occur at some points in the production cycle due to irregular production or increased demand. The effects of shortage on supply chain performance thus need to be studied to fill the gap in existing research. In this paper, we present several seller-buyer supply chain models under a symmetric information structure based on the game-theoretical models introduced in Esmaeili et al. (2009). In the models, demand is assumed sensitive to price and marketing expenditure, and lot size is determined by the buyer. A novel feature of this paper is the introduction of shortage as a decision variable, and the purpose of this paper is to explore the consequences of adding this new element into the existing models. Under the umbrella of a non-cooperative game, we consider the interaction between seller and buyer under two scenarios: (i) Buyer-Stackelberg game where the buyer is the leader and the seller is the follower (ii) Seller-Stackelberg game where the role is switched and the seller becomes the leader and the buyer the follower. We also consider a cooperative game approach where the buyer and seller work together to increase their profit and a Pareto-efficient solution will be obtained for this case.

The rest of this paper is organized as follows. The notation and assumptions underlying the models are given in Section 2, where we also provide model formulation from both the buyer's and seller's perspective. In Section 3, the non-cooperative Seller-Stackelberg and Buyer-Stackelberg games will be discussed including their solutions and Section 4 is devoted to the cooperative game. In Section 5, we present numerical examples illustrating the models, and also to compare between the results obtained when shortages are allowed and when they are not allowed. Section 6 is devoted to a sensitivity analysis involving shortage costs. Finally, the paper is concluded in Section 7 with some suggestions for future work.

\section{Notation and Model Formulation}

The notation and assumptions below are similar to those used in Esmaeili et al. (2009) with the addition of variables related to shortages.

\subsection{Notation and Assumption}

\subsubsection{Decision Variables}

V: The price charged by the seller to the buyer (\$/unit)

$\mathrm{S}$ : The shortage controlled by the seller (units)

Q: Lot size determined by the buyer (units)

P: Selling price charged by the buyer to the customer (\$/unit)

M: Marketing expenditure incurred by the buyer (\$/unit)

\subsubsection{Input Parameters}

$\mathrm{k}$ : Scaling constant for demand function $(\mathrm{k}>0)$

$\mathrm{u}$ : Scaling constant for production $(\mathrm{u}>1)$

i: Percent inventory holding cost per unit per year

$\alpha$ : Price elasticity of demand function $(\alpha>1)$

$\beta$ : Marketing expenditure elasticity of demand $(0<\beta<1, \beta+1<\alpha)$

$A_{b}$ : Buyer's ordering cost (\$/order)

$A_{s}$ : Seller's setup cost (\$/setup)

$\mathrm{C}_{\mathrm{s}}$ : seller's production cost including purchasing cost (\$/unit) 
$\mathrm{C}_{1}$ : Buyer's unit shortage cost (\$/unit)

$\mathrm{C}_{2}$ : seller's unit shortage cost (\$/unit)

r: Seller's production rate (units/cycle)

d: Market demand rate (units/cycle)

$\mathrm{D}(\mathrm{P}, \mathrm{M})$ : Annual demand; for notational simplicity we let $\mathrm{D} \equiv \mathrm{D}(\mathrm{P}, \mathrm{M})$.

\subsubsection{Assumption}

The proposed models in this paper based on the following assumptions:

1) Planning horizon is infinite.

2) Parameters are deterministic and known in advance under symmetric information structure.

3) Lot size is determined by the buyer.

4) The annual demand depends on the selling price and marketing expenditure according to Lee \& Kim (1993), that is:

$$
D(P, M)=k P^{-\alpha} M^{\beta}
$$

5) Shortage are permitted due to irregular production capacity or unanticipated demand, it is controlled by the seller in order to reduce its effect on supply chain system.

6) The production rate is greater than demand rate, and we assume that they are linearly related according to the following equation:

$$
r=u d \quad(u>1)
$$

\subsection{The Buyer's Model Formulation}

The buyer's objection is to determine the order quantity $\mathrm{Q}$ (lot size), selling price $\mathrm{P}$ and marketing expenditure $\mathrm{M}$ so that his net profit is maximized. The buyer's profit function is

Buyer's profit $=$ Sales Revenue - Purchase Cost - Marketing Cost - Ordering Cost - Holding Cost - Shortage Cost.

The holding cost is expressed as a percentage of average positive inventory cost, ie., iVI and shortage cost is expressed as a negative inventory cost, ie., $\mathrm{C}_{1} \mathrm{~B}$. I and $\mathrm{B}$ can be derived using the idea described by Johnson \& Montgomery (1974) according to the inventory fluctuation diagram in Figure 1 below.

$<$ Insert Figure 1 Here $>$

We remark that Figure 1 is a general inventory fluctuation diagram, so it can be used for both buyer and seller to derive the positive inventory and negative inventory during the time span of the inventory process. The positive area on time span $t_{1}$ and $t_{4}$ represent the positive inventory and, the negative area on $t_{2}$ and $t_{3}$ correspond to the negative inventory. Using assumption $\mathrm{T}=\mathrm{Q} / \mathrm{d}$, we have the average positive inventory and negative inventory as

$I=\frac{\left[Q\left(1-u^{-1}\right)-S\right]^{2}}{2 d\left(1-u^{-1}\right)} \frac{d}{Q}=\frac{\left[Q\left(1-u^{-1}\right)-S\right]^{2}}{2 Q\left(1-u^{-1}\right)} \quad$ and $\quad B=\frac{S^{2}}{2 d\left(1-u^{-1}\right)} \frac{d}{Q}=\frac{S^{2}}{2 Q\left(1-u^{-1}\right)} \quad$ respectively. Therefore, the buyer's profit function can be expressed mathematically as:

$$
\begin{aligned}
& \Pi_{b}(M, P, Q)=P D-V D-M D-A_{b} \frac{D}{Q}-i V I-C_{1} B \\
& =k P^{-\alpha+1} M^{\beta}-k V P^{-\alpha} M^{\beta}-k P^{-\alpha} M^{\beta+1}-A_{b} k P^{-\alpha} M^{\beta} Q^{-1} \\
& -\frac{\left[Q\left(1-u^{-1}\right)-S\right]^{2}}{2 Q\left(1-u^{-1}\right)} i V-\frac{C_{1} S^{2}}{2 Q\left(1-u^{-1}\right)}
\end{aligned}
$$

The buyer's model (3) is similar to the buyer's model in Esmaeili et al. (2009) except for the last extra two terms due to shortages which do not involved the variable $P$. Hence, it follows that $\Pi_{b}(M, P, Q)$ is strictly pseudoconcave function with respect to $\mathrm{P}$ for fixed $\mathrm{Q}$ and $\mathrm{M}$ and, concave with respect to $\mathrm{M}$ and $\mathrm{Q}$. Therefore, the first order condition on $\Pi_{b}(\mathrm{M}, \mathrm{P}, \mathrm{Q})$ with respect to $\mathrm{P}$ and $\mathrm{M}$ will determine the unique $\mathrm{P}$ and $\mathrm{M}$ that maximize the profit function, 
that is

$$
\begin{aligned}
P^{*}(M, Q) & =\frac{\alpha\left[Q(V+M)+A_{b}\right]}{Q(\alpha-1)} \\
M^{*}(P, Q) & =\frac{\beta\left[Q(P-V)-A_{b}\right]}{Q(\beta+1)}
\end{aligned}
$$

Solving (4) and (5) simultaneously gives

$$
\begin{aligned}
P^{*}(Q) & =\frac{\alpha\left(Q V+A_{b}\right)}{Q(\alpha-\beta-1)} \\
\text { and } M^{*}(Q) & =\frac{\beta\left(Q V+A_{b}\right)}{Q(\alpha-\beta-1)}
\end{aligned}
$$

Similarly, since $\Pi_{b}(M, P, Q)$ is a concave function of $\mathrm{Q}$ for fixed $\mathrm{M}$ and $\mathrm{P}$, the first order condition with respect to $\mathrm{Q}$ yields

$$
Q^{*}(M, P)=\sqrt{\left(\frac{u S}{u-1}\right)^{2}\left(1+\frac{C_{1}}{V i}\right)+\frac{2 u D A_{b}}{(u-1) V i}}
$$

where D is the demand function (1). Alternatively, substituting (6) and (7) into (3) and using first order condition with respect to $\mathrm{Q}$ yields

$$
\begin{aligned}
& {\left[i\left(1-u^{-1}\right)^{2} V Q^{2}-\left(i V+C_{1}\right) S^{2}\right]\left(V+A_{b} Q^{-1}\right)^{\alpha-\beta}} \\
& =2 k\left(1-u^{-1}\right) A_{b} \alpha^{-\alpha} \beta^{\beta}(\alpha-\beta-1)^{\alpha-\beta}
\end{aligned}
$$

To obtain the optimal solution for buyer, we solve equation (9) for the largest positive root as the optimal $\mathrm{Q}^{*}$, then use (6) and (7) to obtain the optimal $\mathrm{P}^{*}$ and $\mathrm{M}^{*}$.

\subsection{The Seller's Model Formulation}

The seller's objective is to determine the optimal price $\mathrm{V}^{*}$ and allowable shortage $\mathrm{S}^{*}$ such that her net profit is maximized. The annual profit function of the seller is

\section{Seller's profit $=$ Sales Revenue - Production Cost - Setup Cost - Holding Cost - Shortage Cost}

or, mathematically

$$
\begin{aligned}
& \Pi_{s}(S, V)=V D-C_{s} D-A_{s} \frac{D}{Q}-i C_{s} I-C_{2} B \\
& =k V P^{-\alpha} M^{\beta}-k C_{s} P^{-\alpha} M^{\beta}-k A_{s} P^{-\alpha} M^{\beta} Q^{-1} \\
& -\frac{\left[Q\left(1-u^{-1}\right)-S\right]^{2}}{2 Q\left(1-u^{-1}\right)} i C_{s}-\frac{C_{2} S^{2}}{2 Q\left(1-u^{-1}\right)}
\end{aligned}
$$

Note that we have express the holding cost as a percentage of average positive inventory of the production cost, ie., $\mathrm{iC}_{\mathrm{s}} \mathrm{I}$ and the shortage cost as a negative inventory of the production cost of the negative inventory, ie., $\mathrm{C}_{2} \mathrm{~B}$. Since $\mathrm{u}>1$, the function defined by (10) is concave in $\mathrm{S}$ as $\frac{\partial^{2} \Pi_{s}(S, V)}{\partial S^{2}}=-\frac{i C_{s}+C_{2}}{\left(1-u^{-1}\right) Q}<0$. Therefore, the first order condition with respect to $S$ yields the unique $S^{*}$ that maximize $\Pi_{s}(S, V)$ for fixed $V$ which is given by

$$
S^{*}=\frac{C_{s} i Q\left(1-u^{-1}\right)}{C_{s} i+C_{2}}
$$

Substituting (11) into (10) gives 


$$
\Pi_{s}(V)=V D-C_{s} D-A_{s} \frac{D}{Q}-C_{s} i I_{s}^{*}-C_{2} B_{s}^{*}
$$

where $I_{s}^{*}=\frac{C_{2}^{2} Q\left(1-u^{-1}\right)}{2\left(C_{s} i+C_{2}\right)^{2}}$ and $B_{s}^{*}=\frac{C_{s}^{2} i^{2} Q\left(1-u^{-1}\right)}{2\left(C_{s} i+C_{2}\right)^{2}}$ are the optimal positive and negative inventory respectively corresponding to $\mathrm{S}^{*}$. solving $\Pi \mathrm{s}(\mathrm{V})=0$, we obtain a zero profit for the seller at

$$
V_{0}=C_{s}+A_{s} Q^{-1}+C_{s} i I_{s}^{*} D^{-1}+C_{2} B_{s}^{*} D^{-1}
$$

Since equation (12) is a linear increasing function of $\mathrm{V}$, the optimal $\mathrm{V}^{*}$ occurs at the highest price it is possible for the seller to charge the buyer. Therefore

$$
V^{*}=F V_{0}=F\left(C_{s}+A_{s} Q^{-1}+C_{s} i I_{s}^{*} D^{-1}+C_{2} B_{s}^{*} D^{-1}\right)
$$

for some $\mathrm{F}>1$. Through negotiation with the buyer, the seller can obtain a suitable value for $\mathrm{F}$ which the former can bear while allowing the latter to make a profit. Therefore, for any given $\mathrm{Q}, \mathrm{P}$ and $\mathrm{M}$, the optimal shortage and the price charged by the seller is $\mathrm{S}^{*}$ and $\mathrm{V}^{*}$ respectively.

\section{The Non-cooperative Stackelberg Game}

In this section, the seller and buyer interacts with each other through a non-cooperative Stackelberg game, where one player acts as a leader and the other the follower. The leader has the power to make the first move and can enforce her strategy based on the follower's best response. Based on the follower's best strategy, the leader will design a best strategy to maximize her profit.

\subsection{The Seller-Stackelberg Model}

In the Seller-Stackelberg game model, the seller is the leader and the buyer the follower. For a given $\mathrm{V}$ and $\mathrm{S}$ set by the seller, the buyer obtains the best lot size $\mathrm{Q}^{*}$, marketing expenditure $\mathrm{M}^{*}$ and selling price $\mathrm{P}^{*}$ which are the solutions obtained by solving (6), (7) and (9) simultaneously. The seller then maximize her profit with respect to $\mathrm{V}$ and $\mathrm{S}$ based on the triple $\mathrm{Q}^{*}, \mathrm{P}^{*}$ and $\mathrm{M}^{*}$. Thus the problem becomes:

$$
\begin{gathered}
\text { Max } \Pi_{s}(S, V)=V D-C_{s} D-A_{s} \frac{D}{Q}-i C_{s} I-C_{2} B \\
\text { Subject to } P^{*}(Q)=\frac{\alpha\left(Q V+A_{b}\right)}{Q(\alpha-\beta-1)} \\
M^{*}(Q)=\frac{\beta\left(Q V+A_{b}\right)}{Q(\alpha-\beta-1)}
\end{gathered}
$$

and $\left[i\left(1-u^{-1}\right)^{2} V Q^{2}-\left(i V+C_{1}\right) S^{2}\right]\left(V+A_{b} Q^{-1}\right)^{\alpha-\beta}=2 k\left(1-u^{-1}\right) A_{b} \alpha^{-\alpha} \beta^{\beta}(\alpha-\beta-1)^{\alpha-\beta}$

where $\alpha>\beta+1$. Substituting $\mathrm{P}^{*}(\mathrm{Q})$ and $\mathrm{M}^{*}(\mathrm{Q})$ into (15) reduces the problem to

$$
\begin{aligned}
& \operatorname{Max} \Pi_{s}(S, V) \\
& =k \alpha^{-\alpha} \beta^{\beta}(\alpha-\beta-1)^{\alpha-\beta}\left(V+A_{b} Q^{-1}\right)^{-\alpha+\beta}\left(V-C_{s}-A_{s} Q^{-1}\right)-i C_{s} I-C_{2} B \\
& \text { Subject to } \\
& {\left[i\left(1-u^{-1}\right)^{2} V Q^{2}-\left(i V+C_{1}\right) S^{2}\right]\left(V+A_{b} Q^{-1}\right)^{\alpha-\beta}=2 k\left(1-u^{-1}\right) A_{b} \alpha^{-\alpha} \beta^{\beta}(\alpha-\beta-1)^{\alpha-\beta}}
\end{aligned}
$$

transforming the problem into a constrained nonlinear optimization problem with three variables $\mathrm{V}, \mathrm{S}$ and $\mathrm{Q}(\mathrm{V}, \mathrm{S})$. The optimal solution can be found using any nonlinear programming search tools such as Precondition Conjugate Gradient (PCG) method or Sequential Quadratic Programming (SQP) method. In this paper, we will use the nonlinear programming subroutine in the Maple package to solve this problem and a numerical example will be given in Section 5.

\subsection{The Buyer-Stackelberg Model}

Power has shifted from the seller to the buyer in a Buyer-Stackelberg model where the buyer is leader and makes the 
first move. For a given set of decision variables $\mathrm{M}, \mathrm{P}$ and $\mathrm{Q}$ selected by the buyer, the seller obtains the optimal shortage $\mathrm{S}^{*}$ and the best selling price $\mathrm{V}^{*}$ given by (11) and (14) respectively. The buyer then maximize his profit with respect to $\mathrm{M}, \mathrm{P}$ and $\mathrm{Q}$ based on the pair $\mathrm{S}^{*}$ and $\mathrm{V}^{*}$. Thus the problem becomes

$$
\begin{aligned}
\operatorname{Max} \Pi_{b}(M, P, Q)=P D-V D-M D-A_{b} \frac{D}{Q}-i V I-C_{1} B \\
\text { Subject to } S^{*}=\frac{C_{s} i Q\left(1-u^{-1}\right)}{C_{s} i+C_{2}} \\
V^{*}=F\left(C_{s}+A_{s} Q^{-1}+C_{s} i I_{s}^{*} D^{-1}+C_{2} B_{s}^{*} D^{-1}\right)
\end{aligned}
$$

Substituting (19) and (20) into (18) reduces the problem to an unconstrained nonlinear optimization problem. A closed form solution will be given in Appendix derived through an application of Geometric Programming with a $2^{\text {nd }}$ degree of difficulty.

\section{The Cooperative Game}

In this section, we apply a cooperative game approach to the seller-buyer supply chain problem and examine whether both players can increase their profit if they work together to jointly determine the optimal S, V, M, P and Q. A Pareto-efficient solution, defined as the outcome in which there is no other preferable outcome for both players, will be obtained through the joint optimization of the weighted sum of the seller's and buyer's objective functions. The set of Pareto-efficient solution can be derived by maximizing $Z=\lambda \Pi_{s}+(1-\lambda) \Pi_{b} \quad(0<\lambda<1)$. That is

$$
\begin{aligned}
& \operatorname{Max} \mathrm{Z}=\lambda\left(V D-C_{s} D-A_{s} \frac{D}{Q}-i C_{s} I-C_{2} B\right) \\
& +(1-\lambda)\left(P D-V D-M D-A_{b} \frac{D}{Q}-i V I-C_{1} B\right)
\end{aligned}
$$

The first order condition with respect to $\mathrm{V}$ yields

$$
\lambda^{*}=\frac{D+i I}{2 D+i I}
$$

which gives $\lambda \in(0,1)$ as is required.

Next, using the first order condition with respect to Q, P, M and S yield the following equations:

$$
\begin{aligned}
Q^{*} & =\sqrt{\left(\frac{u S}{u-1}\right)^{2}\left(1+\frac{\lambda C_{2}+(1-\lambda) C_{1}}{i\left(\lambda C_{s}+(1-\lambda) V\right)}\right)+\frac{2 u D\left(\lambda A_{s}+(1-\lambda) A_{b}\right)}{(u-1) i\left(\lambda C_{s}+(1-\lambda) V\right)}} \\
P^{*} & =\frac{\alpha\left[(1-\lambda)\left(V Q+A_{b}\right)+\lambda\left(A_{s}+\left(C_{s}-V\right) Q\right]\right.}{Q(\alpha-\beta-1)(1-\lambda)} \\
M^{*} & =\frac{\beta\left[(1-\lambda)\left(V Q+A_{b}\right)+\lambda\left(A_{s}+\left(C_{s}-V\right) Q\right]\right.}{Q(\alpha-\beta-1)(1-\lambda)}
\end{aligned}
$$

and

$$
S^{*}=\frac{i Q(u-1)\left[(1-\lambda) V+\lambda C_{s}\right]}{u\left[(1-\lambda)\left(C_{1}+i V\right)+\lambda\left(C_{2}+i C_{s}\right)\right]}
$$

Pareto-efficient solution can be obtained by solving (22), (23), (24), (25) and (26) simultaneously for a fixed V, which can be determined through negotiation between seller and buyer.

Since the seller would never operate at a loss, using the negotiated $\mathrm{V}$ approach, it is reasonable to expect that $V>C_{s}+A_{s} Q^{-1}+C_{s} i I_{s}^{*} D^{-1}+C_{2} B_{s}^{*} D^{-1}$ (from equation (14) by assuming $\mathrm{F}>1$ ). Under this condition, by comparing (23), (24), (25) and (26) with (6), (7), (8) and (11), we obtain the following interesting results:

i. The optimal selling price in a cooperative game is less than in a non-cooperative game.

Proof: Let $P_{C}^{*}$ and $P_{N}^{*}$ be the optimal selling price in a cooperative and a non-cooperative game respectively. Note 
that $P_{C}^{*}$ is given by (24) and $P_{N}^{*}$ by $(6)$, hence

$$
P_{C}^{*}=P_{N}^{*}-\frac{\alpha \lambda\left(V-C_{s}-A_{s} Q^{-1}\right)}{(\alpha-\beta-1)(1-\lambda)}
$$

By equation (14) and since $\alpha>\beta+1,0<\lambda<1$ and $V>C_{s}+A_{s} Q^{-1}$, (27) implies $P_{C}^{*}<P_{N}^{*}$.

ii. Optimal marketing expenditure in a cooperative game is less than in a non-cooperative game.

Proof: Let $M_{C}^{*}$ and $M_{N}^{*}$ be the marketing expenditure in a cooperative and a non-cooperative game, respectively. Ie., $M_{C}^{*}$ is given by (25) and $M_{N}^{*}$ by (7). Then

$$
M_{C}^{*}=M_{N}^{*}-\frac{\beta \lambda\left(V-C_{s}-A_{s} Q^{-1}\right)}{(\alpha-\beta-1)(1-\lambda)}
$$

and by equation (14), since $\alpha>\beta+1,0<\lambda<1$ and $V>C_{s}+A_{s} Q^{-1}$, (28) implies $M_{C}^{*}<M_{N}^{*}$.

iii. Optimal lot size in cooperative game is greater than in Seller-Stackelberg game if $C_{2} \geq C_{1}$ and $A_{s} \geq A_{b}$.

Proof: Let $Q_{C}^{*}$ and $Q_{S}^{*}$ be the lot size in cooperative and Seller-Stackelberg game respectively, ie., $Q_{C}^{*}$ is given by (23) and $Q_{S}^{*}$ by (8). Equating the two terms given by these two equations result in

$$
\begin{aligned}
\left(\frac{u S}{u-1}\right)^{2}\left(1+\frac{C_{1}}{i\left(\lambda C_{s}+(1-\lambda) V\right.}\right) & +\frac{2 u D A_{b}}{(u-1) i\left(\lambda C_{s}+(1-\lambda) V\right)} \\
& +\left(\frac{u S}{u-1}\right)^{2} \frac{\lambda\left(C_{2}-C_{1}\right)}{i\left(\lambda C_{s}+(1-\lambda) V\right)}+\frac{2 u D \lambda\left(A_{s}-A_{b}\right)}{(u-1) i\left(\lambda C_{s}+(1-\lambda) V\right)}
\end{aligned}
$$

From the assumptions that $\mathrm{C}_{\mathrm{s}}<\mathrm{V}$, it follows that when $\mathrm{C}_{2} \geq \mathrm{C}_{1}$ and $\mathrm{A}_{\mathrm{s}} \geq \mathrm{A}_{\mathrm{b}}$, this will imply $Q_{C}^{*}>Q_{S}^{*}$.

iv. Optimal shortage in cooperative game is less than in a Buyer-Stackelberg game if $C_{1}>\frac{V}{C_{s}} C_{2}$.

Proof: Let $S_{C}^{*}$ and $S_{B}^{*}$ be the optimal shortage in a cooperative and a Buyer-Stackelberg game respectively, ie., $S_{C}^{*}$ is given by (26) and and $S_{B}^{*}$ by (11). We obtain

$$
S_{C}^{*}=S_{B}^{*}-\frac{i Q(u-1)(1-\lambda)\left(C_{1} C_{s}-C_{2} V\right)}{u\left[(1-\lambda)\left(C_{1}+i V\right)+\lambda\left(C_{2}+i C_{s}\right)\right]\left(C_{2}+i C_{s}\right)}
$$

Since $\mathrm{C}_{\mathrm{s}}<\mathrm{V}, 0<\lambda<1$ and $\mathrm{u}>1$, when $C_{1}>\frac{V}{C_{s}} C_{2}$, (29) implies $S_{C}^{*}<S_{B}^{*}$.

\section{Numerical Examples}

This section presents numerical examples to illustrate some significant features of the models established in the previous sections. A comparison between the results of the model with and without shortage (by letting $\mathrm{S}=0$ ) will also be made to reveal its effect on both seller and buyer's profit.

\subsection{Numerical Examples for Non-cooperative and Cooperative Game}

Examples $1-3$ below illustrate the Seller-Stackelberg, Buyer-Stackelberg and cooperative model respectively. In these examples, we set $\mathrm{k}=3500, \alpha=1.7, \beta=0.15, \mathrm{i}=10 \%, \mathrm{Ab}=40, \mathrm{As}=140, \mathrm{u}=1.1, \mathrm{C} 1=1, \mathrm{C} 2=1$ and $\mathrm{Cs}=1.5$.

Example 1. The Seller-Stackelberg model produces the following optimal values for the decision variables: $\mathrm{S}^{*}=$ $28.54, \mathrm{~V}^{*}=4.60, \mathrm{Q}^{*}=622.24, \mathrm{M}^{*}=1.27$ and $\mathrm{P}^{*}=14.42$. The corresponding seller's and buyer's profit is $\Pi_{s}^{*}=103.52$ and $\Pi_{b}^{*}=319.28$ respectively.

Example 2. The Buyer-Stackelberg model produces the following optimal values for the decision variables: $\mathrm{S}^{*}=$ $16.83, \mathrm{~V}^{*}=2.07, \mathrm{Q}^{*}=1419.10, \mathrm{M}^{*}=0.55$ and $\mathrm{P}^{*}=6.26$. The corresponding seller's and buyer's profit is 
$\Pi_{s}^{*}=58.71$ and $\Pi_{b}^{*}=499.72$ respectively.

Comparing the two models, the marketing expenditure $\mathrm{M}^{*}$ and selling price $\mathrm{P}^{*}$ are smaller but the buyer has a higher profit $\Pi_{b}^{*}$ in the second model. The shortage is also less indicating that the second model is better for the buyer. Since production capacity is linearly related to the demand, the buyer is better informed about the end demand and the lot size will be adjusted accordingly, so the buyer would gain more if he is the leader. Also, a larger lot size $\mathrm{Q}^{*}$ is preferred by the seller when she is the follower but her profit will be less.

Example 3. We will obtain Pareto-efficient solution by assuming that seller and buyer has negotiated an agreement on seller price $\mathrm{V}=3$. Using equation (23), (24), (25) and (26), the optimal values are $\mathrm{Q}^{*}=2136.97, \mathrm{P}^{*}=4.88, \mathrm{M}^{*}=$ 0.43 and $\mathrm{S}^{*}=16.67$. From equation (22), $\lambda=0.5096$ and finally we obtain $\mathrm{Z}^{*}=290.61$ using equation (21).

As expected from the results of the previous section, the selling price $\mathrm{P}^{*}$ and the marketing expenditure $\mathrm{M}^{*}$ of the cooperative game are less than in the non-cooperative games. The profit obtained is more than the profit of the seller for both the Seller-Stackelberg and Buyer-Stackelberg models. The lot size is also greater than in the non-cooperative games. Therefore, the seller would prefer the cooperative model to the non-cooperative models. On the other hand, the buyer might also prefer the cooperative model since the shortage in the cooperative game is less than in the non-cooperative games.

\subsection{Numerical Results from Models with and without Shortages}

To obtain some understanding of the effects to both seller and buyer's decision variables and profits caused by shortages, it is worthwhile to compare the numerical results obtained from the two cases. In the following, the symbol NS represents no shortage and all parameters are the same as the ones used in the previous examples.

In the Seller-Stackelberg game, the optimal decision variables in the $N S$ case are $\mathrm{V}^{N S}=4.41, \mathrm{Q}^{N S}=284.02, \mathrm{P}^{N S}=$ 14.06 and $\mathrm{M}^{N S}=1.24$. The seller's profit is $\Pi_{s}^{N S}=97.61$ and buyer's profit is $\Pi_{b}^{N S}=328.55$. Compare with the corresponding results from the shortage model, both buyer's and seller's selling prices are smaller in the NS case as a consequence of the absence of shortage. Also, the order quantity and marketing expenditure are larger than in the $N S$ model. The seller's profit in the shortage model is larger than in the NS model, whereas the buyer's profit is smaller in the NS model. Hence, in the Seller-Stackelberg game, the seller has an advantage of being the leader and controlling the shortage whereas for the buyer, the shortage has a negative impact on his profit.

In the Buyer-Stackelberg game, the corresponding results for the $N S$ models are $\mathrm{V}^{N S}=2.09, \mathrm{Q}^{N S}=1303.71, \mathrm{P}^{N S}=$ 6.29 and $\mathrm{M}^{N S}=0.56$. The buyer's profit is $\Pi_{b}^{N S}=496.07$ and the seller's profit is $\Pi_{s}^{N S}=58.66$. Comparing the results with the shortage model, show that the buyer has a lower selling price and larger order quantity than in the $N S$ model. Both the seller and the buyer's profit in the shortage model is higher than in the NS model. This is due to the presence of shortage which induces the buyer to order larger quantity in order to satisfy demand and avoid a loss of profit, which in turn would favor the seller.

In the cooperative game, the following results were obtained for the $N S$ game: $\mathrm{P}^{N S}=4.92, \mathrm{M}^{N S}=0.43$ and $\mathrm{Q}^{N S}=$ 1354.03. The optimal weight is $\lambda=0.5074$ and the profit is $\mathrm{Z}^{N S}=279.65$. Comparing these results with the shortage case indicate that the buyer's selling price in the shortage model is less than in the NS model, resulting in a larger order quantity as well as a larger profit. This further emphasizes the value of cooperation since both seller and buyer can do better by cooperating with each other even in the presence of shortages.

\section{Sensitivity Analysis}

In this section, we will carry out the investigation of how the changes in buyer's or seller's unit shortage cost, $\mathrm{C}_{1}$ or $\mathrm{C}_{2}$, will affect their decisions and profits for the different models through a sensitivity analysis. In the following, the input parameters will be the same as in the previous examples but we allow $\mathrm{C}_{1}$ and $\mathrm{C}_{2}$ to vary. We let $\mathrm{F}=1.25$ in the Buyer-Stackelberg model and the negotiated selling price $\mathrm{V}=3$ in the cooperative model.

The effects of parameters $\mathrm{C}_{1}$ and $\mathrm{C}_{2}$ on decision variables $\mathrm{S}^{*}, \mathrm{~V}^{*}, \mathrm{P}^{*}, \mathrm{Q}^{*}, \mathrm{M}^{*}$ and profits $\Pi_{b}^{*}$ and $\Pi_{s}^{*}$ in the non-cooperative games will be investigated through the following sensitivity analysis. Similarly, the effects of parameters $\mathrm{C}_{1}$ and $\mathrm{C}_{2}$ on $\mathrm{P}^{*}, \mathrm{Q}^{*}, \mathrm{M}^{*}, \mathrm{~S}^{*}$ and $\mathrm{Z}^{*}$ will also be investigated in the cooperative game. The results of the 
analysis are displayed in Table 1 to Table 6.

$<$ Insert Table 1 to Table 6 Here $>$

The results show that varying $\mathrm{C}_{1}$ and $\mathrm{C}_{2}$ will affect both seller and buyer's profit in different ways for different models. For instance, increasing $\mathrm{C}_{1}$ (or $\mathrm{C}_{2}$ ) in the Seller-Stackelberg game results in the buyer's profit $\Pi_{b}^{*}$ (or seller's profit $\Pi_{s}^{*}$ ) declining, whereas the seller's profit $\Pi_{s}^{*}$ (or buyer's profit $\Pi_{b}^{*}$ ) will increase. Increasing either $\mathrm{C}_{1}$ or $\mathrm{C}_{2}$ will result in both seller's and buyer's profit in the Buyer-Stackelberg game and the joint profit in the cooperative game to decline.

The effect of parameter $\mathrm{C} 1$ on decision variables $\mathrm{V}^{*}, \mathrm{~S}^{*}, \mathrm{Q}^{*}, \mathrm{P}^{*}$ and $\mathrm{M}^{*}$ are demonstrated in Figure 2 . The number 1 , 2 and 3 in each figure refers to the Seller-Stackelberg, Buyer-Stackelberg and the cooperative game respectively.

$<$ Insert Figure 2 Here $>$

From the graphs, by increasing $C_{1}$ in the Seller-Stackelberg game, the seller's shortage size $S^{*}$ increase before $C_{1}$ reaches $C_{2}$, and decreases when it exceeds $C_{2}$ which cause seller's selling price $V^{*}$ and buyer's selling price $P^{*}$, marketing expenditure $\mathrm{M}^{*}$ to decrease and then increase accordingly. This indicate that in the Seller-Stackelberg game, the decision variables $\mathrm{S}^{*}, \mathrm{~V}^{*}, \mathrm{P}^{*}$ and $\mathrm{M}^{*}$ will be affected by both $\mathrm{C}_{1}$ and $\mathrm{C}_{2}$. However, in the Buyer-Stackelberg game, when the buyer is the leader, as $\mathrm{C}_{1}$ increases, the shortage size $\mathrm{S}^{*}$ decreases whereas $\mathrm{V}^{*}, \mathrm{P}^{*}$ and $\mathrm{M}^{*}$ increase. Therefore, by varying $C_{1}$, it is seen that the behavior of the decision variables $\mathrm{S}^{*}, \mathrm{~V}^{*}, \mathrm{P}^{*}$ and $\mathrm{M}^{*}$ are dependent on the players' leadership position. Also, the buyer's order quantity is dependent on his leadership position, ie., his order quantity is decreasing in the Buyer-Stackelberg game and increasing in the Seller-Stackelberg game.

The effect of parameter $\mathrm{C}_{2}$ on $\mathrm{P}^{*}, \mathrm{Q}^{*}, \mathrm{M}^{*}, \mathrm{~S}^{*}$ and $\mathrm{V}^{*}$ are graphically displayed in Figure 3.

$<$ Insert Figure 3 Here $>$

As $\mathrm{C}_{2}$ increases, the seller's decision variable $\mathrm{S}^{*}$ decreases regardless of whether the seller is the leader or the follower. However, the changes in variables $\mathrm{P}^{*}, \mathrm{M}^{*}, \mathrm{Q}^{*}$ and $\mathrm{V}^{*}$ are dependent on the leadership position of the participant. For instance, as $\mathrm{C}_{2}$ increases, $\mathrm{P}^{*}$ decreases and then increases in the Seller-Stackelberg but show the reverse trend in the Buyer-Stackelberg game.

Finally, the graphs also indicate that the shortage in a cooperative game is less than in the non-cooperative game when $C_{1}>\frac{V}{C_{s}} C_{2}$. Also, the order quantity $\mathrm{Q}^{*}$ is greater, and the selling price $\mathrm{P}^{*}$, marketing expenditure $\mathrm{M}^{*}$ is

smaller in the cooperative game than in the non-cooperative games. These observations are consistent with the results obtained in Section 4.

\section{Conclusion}

In this paper, we have extended the seller-buyer supply chain management problem under a symmetric information structure considered in Esmaeili et al. (2009) by incorporating the likelihood of shortages into the models. This is an essential generalization due to the presence of irregular production capacity or unanticipated demands. In the non-cooperative game scenario, two types of games are discussed: Seller-Stacklelberg game and Buyer-Stackelberg game. Optimal solutions of the decision variables were obtained for both of these cases. In the cooperative game, Pareto-efficient solutions were obtained by optimizing the weighted sum of the seller's and buyer's profit functions. Among several conclusions reached, it was shown that both selling price and marketing expenditure are smaller in cooperative game than in non-cooperative games and demand is larger. In addition, shortages are smaller in a cooperative game than in a non-cooperative game when the buyer's unit shortage cost is larger than the seller's unit shortage cost, which is the case most likely to be encountered in practice. Numerical examples were presented to illustrate the results from the models and to compare between non-cooperative and cooperative game, with and without shortages. Furthermore, sensitivity analysis was carried out to investigate the effects of the unit shortage costs on the optimal solutions.

Finally, we conclude this paper with some suggestions for extending the present work. For example, the two-person game scenario considered in this paper can be extended to a three-person game by adding consumer as the third 
person to assess how the effect of shortage will affect the welfare of the latter. This will lead to many interesting sets of interactions between the players. Also, all input parameters in this paper are assumed known to both players whereas, in reality, costs such as shortage cost, setup cost and demand are often not common knowledge and should not be assumed as such. In this case, asymmetric information rules the game and incentive strategies or designs may have to be devised for the players to share or reveal their private information.

\section{Appendix: Geometric Programming Solution of the Buyer-Stackelberg Game}

We show how Geometric Programming can be used to obtain a closed form solution for Buyer-Stackelberg game. Substituting (19) and (20) into (18), and after some algebra simplifications, the problem becomes:

$$
\begin{aligned}
& \operatorname{Max} \Pi_{b}(M, P, Q)=k P^{-\alpha+1} M^{\beta}-k P^{-\alpha} M^{\beta+1}-k F C_{s} P^{-\alpha} M^{\beta} \\
& -k\left(F A_{s}+A_{b}\right) P^{-\alpha} M^{\beta} Q^{-1}-A_{1} Q-A_{2} Q^{2} P^{\alpha} M^{-\beta}-A_{3}
\end{aligned}
$$

where

$$
\begin{aligned}
A_{1} & =\frac{0.5 i C_{s}\left[C_{2}^{2}(F+1)+i C_{s}\left(C_{1}+C_{2}\right)\right]\left(1-u^{-1}\right)}{\left(i C_{s}+C_{2}\right)^{2}} \\
A_{2} & =\frac{0.25 i^{2} F C_{s} C_{2}^{3}\left(1-u^{-1}\right)^{2} k^{-1}}{\left(i C_{s}+C_{2}\right)^{3}} \\
\text { and } A_{3} & =\frac{0.5 i F A_{s} C_{2}^{2}\left(1-u^{-1}\right)}{\left(i C_{s}+C_{2}\right)^{2}}
\end{aligned}
$$

We next transform this Signomial Problem with $2^{\text {nd }}$ degree of difficulty into a Posinomial Problem by using the method developed by Duffin, Peterson and Zener (1967). The solution of the Posinomial Problem can then be obtained by solving its Dual problem. Ignoring the last term in (30) the Posinomial problem is:

$$
\begin{aligned}
& \text { Max } Z=\Pi_{b} \text { or } \operatorname{Min} Z^{-1} \\
& \text { Subject to } k^{-1} Z P^{\alpha-1} M^{-\beta}+P^{-1} M+F C_{s} P^{-1}+\left(F A_{s}+A_{b}\right) P^{-1} Q^{-1} \\
& +k^{-1} A_{1} P^{\alpha-1} M^{-\beta} Q+k^{-1} A_{2} P^{2 \alpha-1} M^{-2 \beta} Q^{2}<1
\end{aligned}
$$

Therefore the Dual Problem (DPZ) is:

$$
\begin{aligned}
& \text { Max }\left(\frac{1}{\omega_{0}}\right)^{\omega_{0}}\left(\frac{k^{-1}}{\omega_{1}}\right)^{\omega_{1}}\left(\frac{1}{\omega_{2}}\right)^{\omega_{2}}\left(\frac{F C_{s}}{\omega_{3}}\right)^{\omega_{3}}\left(\frac{F A_{s}+A_{b}}{\omega_{4}}\right)^{\omega_{4}}\left(\frac{k^{-1} A_{1}}{\omega_{5}}\right)^{\omega_{5}}\left(\frac{k^{-1} A_{2}}{\omega_{6}}\right)^{\omega_{6}} \lambda^{\lambda} \\
& \text { Subject to } \begin{aligned}
1 & =\omega_{0} \\
0 & =-\omega_{0}+\omega_{1} \\
0 & =(\alpha-1) \omega_{1}-\omega_{2}-\omega_{3}-\omega_{4}+(\alpha-1) \omega_{5}+(2 \alpha-1) \omega_{6} \\
0 & =-\beta \omega_{1}+\omega_{2}-\beta \omega_{5}-2 \beta \omega_{6} \\
0 & =-\omega_{4}+\omega_{5}+2 \omega_{6} \\
\lambda & =\omega_{1}+\omega_{2}+\omega_{3}+\omega_{4}+\omega_{5}+\omega_{6}
\end{aligned}
\end{aligned}
$$

The first constraint above is the normality constraint and the other constraints are the orthogonality constraints. Since the degree of difficulty is 2 , we can rewrite the constraints in terms of $\omega_{5}$ and $\omega_{6}$, ie.,

$$
\begin{array}{ll} 
& \omega_{0}=1 \\
& \omega_{1}=1 \\
& \omega_{2}=\beta+\beta \omega_{5}+2 \beta \omega_{6} \\
& \omega_{3}=(\alpha-\beta-1)+(\alpha-\beta-2) \omega_{5}+(2 \alpha-2 \beta-3) \omega_{6} \\
& \omega_{4}=\omega_{5}+2 \omega_{6} \\
\text { and } \quad \lambda=\alpha\left(1+\omega_{5}+2 \omega_{6}\right) .
\end{array}
$$

Substituting these constrains into (33), then taking logarithm, we can fine the optimal $\omega_{5}$ and $\omega_{6}$ through a line search. Finally, we obtain the optimal solution for $\mathrm{P}, \mathrm{M}$ and $\mathrm{Q}$ in terms of $\omega_{5}$ and $\omega_{6}$ as follow: 


$$
\begin{aligned}
P^{*} & =F C_{s} \frac{\alpha+\alpha \omega_{5}+2 \alpha \omega_{6}}{(\alpha-\beta-1)+(\alpha-\beta-2) \omega_{5}+(2 \alpha-2 \beta-3) \omega_{6}} \\
M^{*} & =F C_{s} \frac{\beta+\beta \omega_{5}+2 \beta \omega_{6}}{(\alpha-\beta-1)+(\alpha-\beta-2) \omega_{5}+(2 \alpha-2 \beta-3) \omega_{6}} \\
\text { and } \quad Q^{*} & =\frac{F A_{s}+A_{b}}{F C_{s}} \frac{(\alpha-\beta-1)+(\alpha-\beta-2) \omega_{5}+(2 \alpha-2 \beta-3) \omega_{6}}{\omega_{5}+2 \omega_{6}}
\end{aligned}
$$

\section{References}

Abad, P. L. (1994). Supplier pricing and lot sizing when demand is price sensitive. European Journal of Operational Research, 78, 334-354. http://dx.doi.org/ 10.1016/0377-2217(94)90044-2

Abad, P. L., \& Jaggi, C. K. (2003). A joint approach for setting unit price and the length of the credit period for a seller when end demand is price sensitive. International Journal of Production Economics, 83, $115-122$. http://dx.doi.org/10.1016/s0925-5273(02)00142-1

Chen, M. S., Chang, H. J., Huang, C. W., \& Liao, C. N. (2006). Channel coordination and transaction cost: A game-theoretic analysis. Industrial Marketing $\quad$ Management, $\quad 35, \quad 178-190$. http://dx.doi.org/10.1016/j.indmarman.2005.03.007

Chiang, W. C., Fitzsimmons, J., Huang, Z., \& Li, S. X. (1994). A Game-Theoretic Approach to Quantity Discount Problems*. Decision Sciences, 25, 153-168. http://dx.doi.org/ 10.1111/j.1540-5915.1994.tb00521.x

Corbett, C. J., \& De Groote, X. (2000). A supplier's optimal quantity discount policy under asymmetric information. Management Science, 46, 444-450. http://dx.doi.org/10.1287/mnsc.46.3.444.12065

Dai, Y., Chao, X., Fang, S. C., \& Nuttle, H. L. W. (2005). Pricing in revenue management for multiple firms competing for customers. International Journal of Production Economics, 98, 1-16. http://dx.doi.org/10.1016/j.ijpe.2004.06.056

Duffin, R. J., Peterson, E. L., \& Zener, C. (1967). Geometric programming: theory and application. New York, Wiley.

Esmaeili, M., \& Zeephongsekul, P. (2010). Seller-buyer models of supply chain management with an asymmetric information structure. International Journal of Production Economics, 123, $146-154$. http://dx.doi.org/10.1016/j.ijpe.2009.07.016

Esmaeili, M., Aryanezhad, M. B., \& Zeephongsekul, P. (2009). A game theory approach in seller-buyer supply chain. European Journal of Operational Research, 195, 442-448. http://dx.doi.org/ 10.1016/j.ejor.2008.02.026

Freeland, J. R. (1980). Coordination strategies for production and marketing in a functionally decentralized firm. AIIE Transactions, 12, 126-132. http://dx.doi.org/10.1080/05695558008974499

Gao, A. Y., \& Liu, K. (2008). Research on Purchasing Supply Chain Coordination Mechanism for Multiple Suppliers with Incomplete Information. Wuhan, Hubei, China. IEEE, 1, 514-517. http://dx.doi.org/10.1109/ISBIM.2008.238

Jaber, M., \& Goyal, S. (2008). Coordinating a three-level supply chain with multiple suppliers, a vendor and multiple buyers. International Journal of Production Economics, 116, 95-103. http://dx.doi.org/10.1016/j.1jpe.2008.08.001

Johnson, L. A., \& Montgomery, D. C. (1974). Operations research in production planning, scheduling, and inventory control. New York, Wiley.

Jüttner, U., Christopher, M., \& Baker, S. (2007). Demand chain management-integrating marketing and supply chain management. Industrial Marketing Management, 36, 377-392. http://dx.doi.org/10.1016/j.indmarman.2005.10.003

Kim, D., \& Lee, W. J. (1998). Optimal joint pricing and lot sizing with fixed and variable capacity. European Journal of Operational Research, 109, 212-227. http://dx.doi.org/ 10.1016/s0377-2217(97)00100-8

Lau, A. H. L., \& Lau, H. S. (2005). Some two-echelon supply-chain games: Improving from deterministic-symmetric-information to stochastic-asymmetric-information models. European Journal of Operational Research, 161, 203-223. http://dx.doi.org/10.1016/j.ejor.2003.08.040

Lee, W. J., \& Kim, D. (1993). Optimal and heuristic decision strategies for integrated production and marketing planning. Decision Sciences, 24, 1203-1214. http://dx.doi.org/ 10.1111/j.1540-5915.1993.tb00511.x

Li, S. X., Huang, Z., Zhu, J., \& Chau, P. Y. K. (2002). Cooperative advertising, game theory and manufacturer-retailer supply chains. Omega, 30, 347-357. http://dx.doi.org/10.1016/S0305-0483(02)00051-8 
Sadjadi, S. J., Oroujee, M., \& Aryanezhad, M. B. (2005). Optimal production and marketing planning. Computational Optimization and Applications, 30, 195-203. http://dx.doi.org/10.1007/s10589-005-4564-8

Sarmah, S. P., Acharya, D., \& Goyal, S. K. (2006). Buyer vendor coordination models in supply chain management. European Journal of Operational Research, 175, 1-15. http://dx.doi.org/10.1016/j.ejor.2005.08.006

Viswanathan, S., \& Wang, Q. (2003). Discount pricing decisions in distribution channels with price-sensitive demand. European Journal of Operational Research, 149, 571-587. http://dx.doi.org/10.1016/S0377-2217(02)00469-1

Weng, Z. K. (1995). Channel coordination and quantity discounts. Management Science, 41, 1509-1522. http://dx.doi.org/10.1287/mnsc.41.9.1509

Yang, S. L., \& Zhou, Y. W. (2006). Two-echelon supply chain models: Considering duopolistic retailers' different competitive behaviors. International Journal of Production Economics, 103, 104-116. http://dx.doi.org/10.1016/j.ijpe.2005.06.001

Table 1. Sensitivity analysis of the Seller-Stackelberg model with respect to C1

\begin{tabular}{lllllll}
\hline $\mathrm{C} 1$ & 0.1 & 0.5 & 1 & 5 & 10 & 15 \\
\hline $\mathrm{P}^{*}$ & 14.86 & 14.66 & 14.43 & 14.34 & 14.42 & 14.47 \\
$\mathrm{~V}^{*}$ & 4.69 & 4.66 & 4.6 & 4.6 & 4.63 & 4.64 \\
$\mathrm{Q}^{*}$ & 343.7 & 489.29 & 621.87 & 972.49 & 1051.68 & 1072.52 \\
$\mathrm{M}^{*}$ & 1.31 & 1.29 & 1.27 & 1.26 & 1.27 & 1.28 \\
$\mathrm{D}^{*}$ & 37.1 & 37.89 & 38.83 & 39.22 & 38.85 & 38.66 \\
$\mathrm{~S}^{*}$ & 18.18 & 25.87 & 28.53 & 24.61 & 19.42 & 16.35 \\
$\Pi^{*}$ & 97.56 & 100.79 & 103.53 & 108.92 & 109.84 & 110.05 \\
$\Pi \mathrm{b}^{*}$ & 322.45 & 321.13 & 319.14 & 302.99 & 295.83 & 292.78 \\
\hline
\end{tabular}

Table 2. Sensitivity analysis of the Seller-Stackelberg model with respect to C2

\begin{tabular}{lllllll}
\hline $\mathrm{C} 2$ & 0.1 & 0.5 & 1 & 3 & 5 & 10 \\
\hline $\mathrm{P}^{*}$ & 14.08 & 14.25 & 14.43 & 14.49 & 14.42 & 14.43 \\
$\mathrm{~V}^{*}$ & 4.53 & 4.56 & 4.6 & 4.56 & 4.52 & 4.52 \\
$\mathrm{Q}^{*}$ & 1628.65 & 891.11 & 621.87 & 312.3 & 277.03 & 274.94 \\
$\mathrm{M}^{*}$ & 1.24 & 1.26 & 1.27 & 1.28 & 1.27 & 1.27 \\
$\mathrm{D}^{*}$ & 40.31 & 39.59 & 38.83 & 38.57 & 38.84 & 38.8 \\
$\mathrm{~S}^{*}$ & 81.45 & 43.12 & 28.53 & 7.74 & 1.73 & 0.52 \\
$\Pi^{*}$ & 114.26 & 108.04 & 103.53 & 96.46 & 95.83 & 95.74 \\
$\Pi \mathrm{b}^{*}$ & 304.76 & 316.29 & 319.14 & 324.26 & 324.57 & 324.03 \\
\hline
\end{tabular}

Table 3. Sensitivity analysis of the Buyer-Stackelberg model with respect to $\mathrm{C} 1$

\begin{tabular}{lllllll}
\hline $\mathrm{C} 1$ & 0.1 & 0.5 & 1 & 5 & 10 & 15 \\
\hline $\mathrm{P}^{*}$ & 6.24 & 6.25 & 6.26 & 6.31 & 6.36 & 6.41 \\
$\mathrm{~V}^{*}$ & 2.07 & 2.07 & 2.07 & 2.08 & 2.09 & 2.1 \\
$\mathrm{Q}^{*}$ & 1454.44 & 1438.43 & 1419.1 & 1286.74 & 1161.48 & 1065.03 \\
$\mathrm{M}^{*}$ & 0.55 & 0.55 & 0.55 & 0.56 & 0.56 & 0.57 \\
$\mathrm{D}^{*}$ & 142.22 & 142.03 & 141.8 & 140.08 & 138.15 & 136.39 \\
$\mathrm{~S}^{*}$ & 17.25 & 17.06 & 16.83 & 15.26 & 13.77 & 12.63 \\
$\Pi s^{*}$ & 58.91 & 58.84 & 58.78 & 58.25 & 57.68 & 57.22 \\
$\Pi \mathrm{b}^{*}$ & 500.72 & 500.27 & 499.72 & 495.54 & 490.82 & 486.53 \\
\hline
\end{tabular}


Table 4. Sensitivity analysis of the Buyer-Stackelberg model with respect to C2

\begin{tabular}{lllllll}
\hline $\mathrm{C} 2$ & 0.1 & 0.5 & 1 & 3 & 5 & 10 \\
\hline $\mathrm{P}^{*}$ & 6.36 & 6.25 & 6.26 & 6.28 & 6.28 & 6.29 \\
$\mathrm{~V}^{*}$ & 2.05 & 2.06 & 2.07 & 2.08 & 2.08 & 2.09 \\
$\mathrm{Q}^{*}$ & 1185.15 & 1457.84 & 1419.1 & 1351.94 & 1333.83 & 1319.2 \\
$\mathrm{M}^{*}$ & 0.56 & 0.55 & 0.55 & 0.55 & 0.55 & 0.55 \\
$\mathrm{D}^{*}$ & 138.37 & 142.16 & 141.8 & 141.04 & 140.83 & 140.64 \\
$\mathrm{~S}^{*}$ & 64.64 & 30.58 & 16.83 & 5.85 & 3.53 & 2.09 \\
$\Pi \mathrm{s}^{*}$ & 56.77 & 58.62 & 58.78 & 58.76 & 58.72 & 58.68 \\
$\Pi \mathrm{b}^{*}$ & 492.06 & 500.84 & 499.72 & 497.66 & 497.08 & 496.59 \\
\hline
\end{tabular}

Table 5. Sensitivity analysis of the cooperative game with respect to $\mathrm{C} 1$

\begin{tabular}{lllllll}
\hline $\mathrm{C} 1$ & 0.1 & 0.5 & 1 & 5 & 10 & 15 \\
\hline $\mathrm{P}^{*}$ & 4.87 & 4.88 & 4.88 & 4.89 & 4.9 & 4.89 \\
$\mathrm{~V}^{*}$ & 3 & 3 & 3 & 3 & 3 & 3 \\
$\mathrm{Q}^{*}$ & 2206.7 & 2161.15 & 2136.97 & 2063.22 & 2047.14 & 2025.29 \\
$\mathrm{M}^{*}$ & 0.43 & 0.43 & 0.43 & 0.43 & 0.43 & 0.43 \\
$\mathrm{~S}^{*}$ & 28.72 & 21.53 & 16.67 & 5.88 & 3.04 & 1.93 \\
$\mathrm{Z}^{*}$ & 291.14 & 290.83 & 290.61 & 290.13 & 290.02 & 289.96
\end{tabular}

Table 6. Sensitivity analysis of the cooperative game with respect to C2

\begin{tabular}{lllllll}
\hline $\mathrm{C} 2$ & 0.1 & 0.5 & 1 & 3 & 5 & 10 \\
\hline $\mathrm{P}^{*}$ & 4.88 & 4.88 & 4.88 & 4.89 & 4.89 & 4.88 \\
$\mathrm{~V}^{*}$ & 3 & 3 & 3 & 3 & 3 & 3 \\
$\mathrm{Q}^{*}$ & 2214.53 & 2160.6 & 2136.97 & 2081.44 & 2051.88 & 2033.32 \\
$\mathrm{M}^{*}$ & 0.43 & 0.43 & 0.43 & 0.43 & 0.43 & 0.43 \\
$\mathrm{~S}^{*}$ & 28.44 & 21.35 & 16.67 & 8.58 & 5.2 & 3.09 \\
$\mathrm{Z}^{*}$ & 291.15 & 290.83 & 290.61 & 290.25 & 290.12 & 290.01 \\
\hline
\end{tabular}

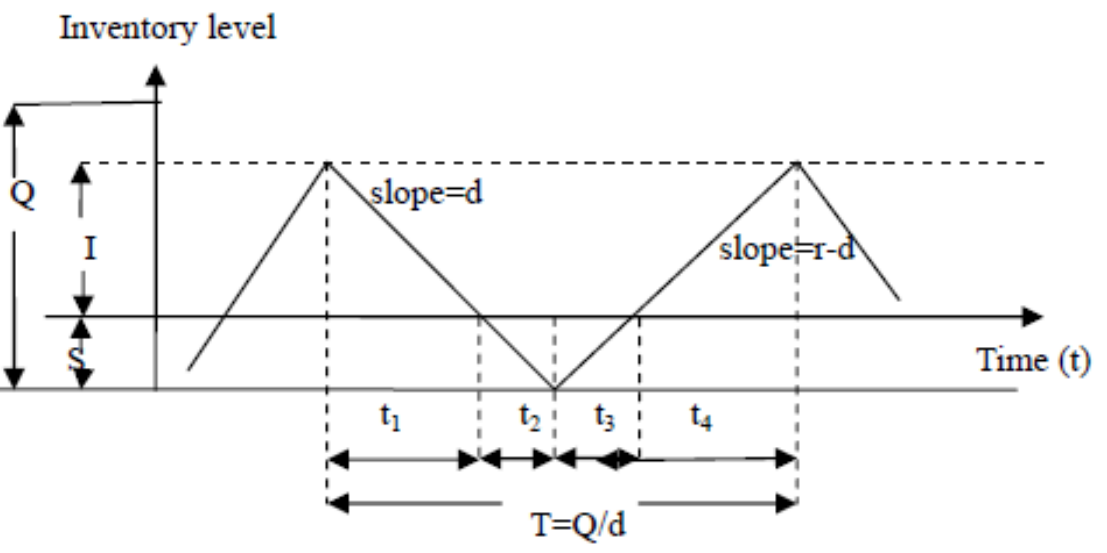

Figure 1. Inventory fluctuation diagram 


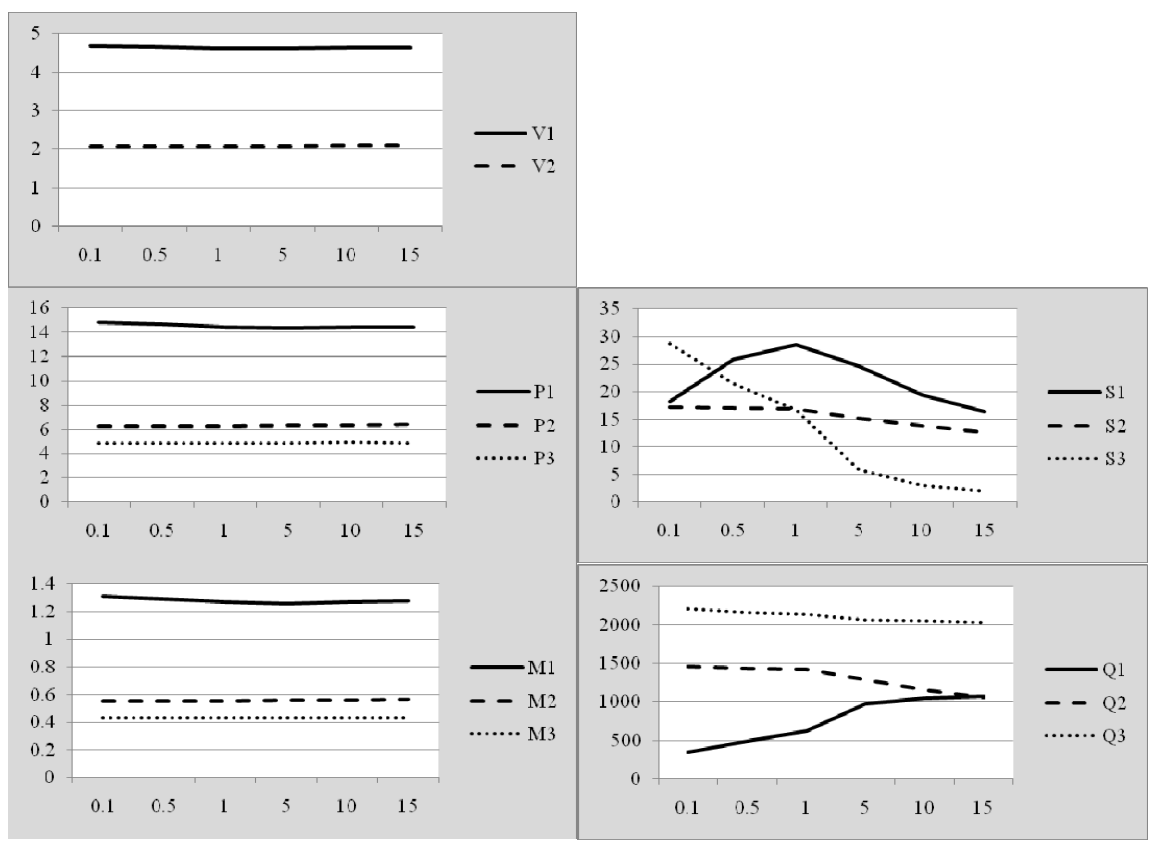

Figure 2. The effect of parameter $\mathrm{C}_{1}$ on $\mathrm{P}^{*}, \mathrm{Q}^{*}, \mathrm{M}^{*}, \mathrm{~S}^{*}$ and $\mathrm{V}^{*}$

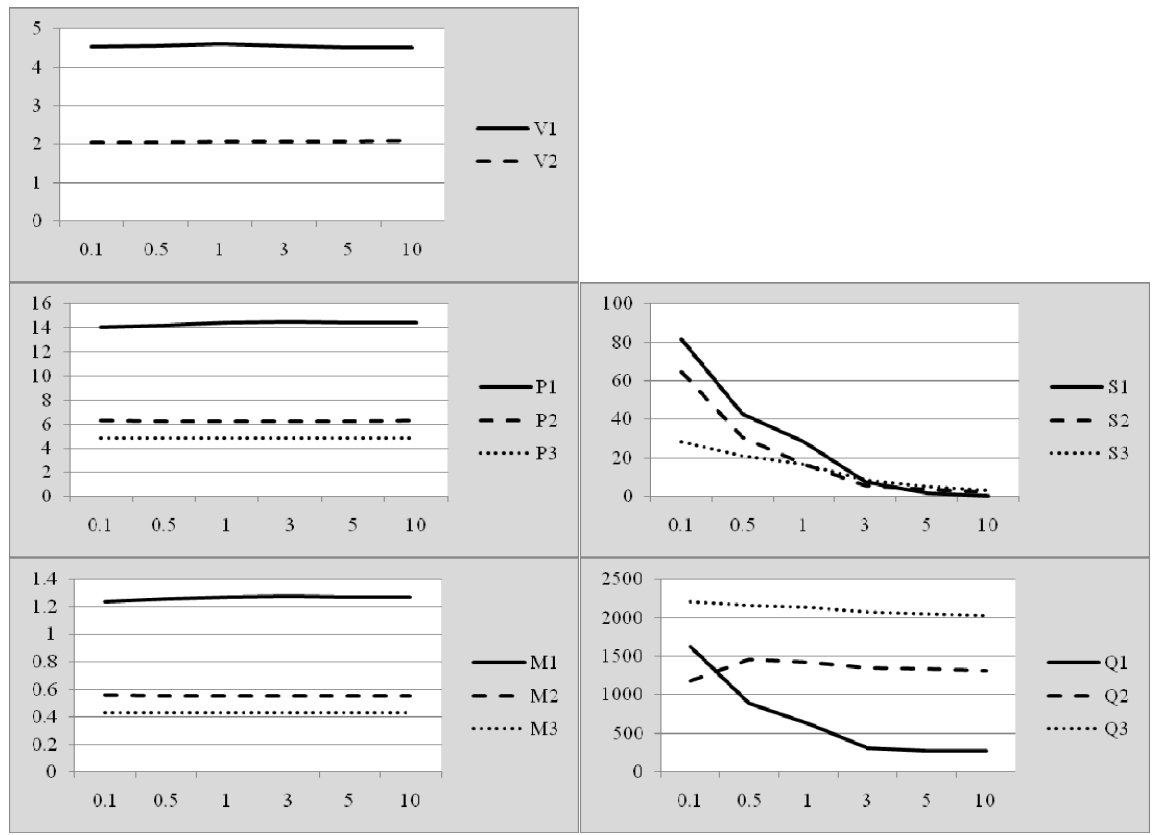

Figure 3. The effect of parameter $C_{2}$ on $P^{*}, Q^{*}, M^{*}, S^{*}$ and $V^{*}$ 